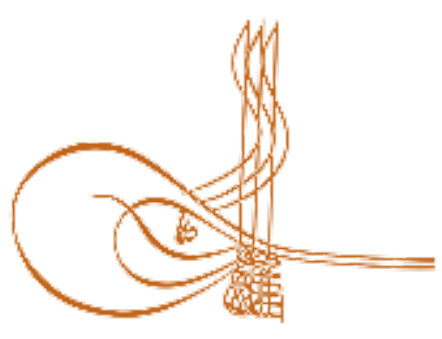

www.turkishstudies.net/education
TurkishStudies-EducationalSciences

eISSN: 2667-5609

ResearchArticle / Araştırma Makalesi

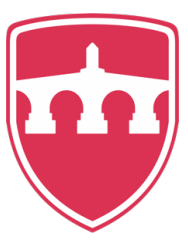

INTERNATIONAL BALKAN

UNIVERSITY Sponsoredby IBU

\title{
Eğitim Yönetimi Yüksek Lisans Programlarının Verimliliğinin İncelenmesi*
}

Investigation of Educational Management Master Programs' Efficiency

\author{
Mehmet Özcan **
}

\begin{abstract}
The aim of this study is to investigate efficiency of master programmes on educational management according to independent variables. Quantitative study techniques were used in this research. This is a descriptive research designed as survey model. This study aims to describe current situation of educational management master programmes and students' ideas towards these programmes at universities. Descriptive statistics were used and $p<.05$ was considered statistically significant. At this study 'efficiency scale' developed by Özcan (2014) was used. The scale is consisted of 25 items and 3 sub-dimensions. Subdimensions of the scale are 'master programme courses and evaluation', 'beneficiary level of the participants from the program', 'physical conditions and lecturing'. Kaiser-Meyer-Olkin (KMO) value of the scale is .935 , and Bartlett's test of sphericity value of the scale is 4813,985. In addition Cronbach Alpha value is .91, Spearman-Brown coefficient is 89 , Guttman coefficient is .88 . The study was conducted 334 participants. Participants are the students studying educational management master degree at different universities. Study group was determined by purposive sampling method. Age, Professional experience, school type, administrative position and master programme type were independent variables of the study. According to age variable, students' in different career stages' expectations and ideas on master programme show differences. As professional experience increases, students' efficiency expectations show differences. School type does not significantly differ the efficiency of master programs. Administrative position significantly differ efficiency of the master program and the difference is between school manager and vice manager. Master type does not significantly differ efficiency of the program. According to the research results age variable significantly differ the efficiency of master degree. Professional experience significantly differ the efficiency of master degree. School type does not significantly differ the efficiency of master degree. Administrative position significantly differ efficiency of the master program and the difference is between school manager and vice manager. Master type does not significantlydiffer efficiency of the program.
\end{abstract}

Structured Abstract: Introduction Education is one of the most important effect of a community's development and this effect has been studied by researchers. Education is defined as development of a person's physical, ideal and moral values (Lederman, 1992). Education has been divided to specific research

*Bu çalışma Eğitim Yönetimi Denetimi Planlaması ve Ekonomisi Yüksek Lisans Programının Verimliliğinin ve Etkililiğinin Değerlendirilmesi adlı doktora tezinden üretilmiştir.

${ }^{* *}$ Dr. Öğr. Üyesi, Nevşehir Hacı Bektaş Veli Üniversitesi, Eğitim Fakültesi, Eğitim Bilimleri Bölümü

Assist. Prof. Dr. Nevsehir Haci Bektas Veli University, Department of Educational Sciences

ORCID0000-0002-5451-0773

mehmetozcan79@gmail.com

Cite as/ Atıf: Özcan, M. (2020). Eğitim yönetimi yüksek lisans programlarının verimliliğinin incelenmesi,

TurkishStudies-Education, 15(2), 1127-1140. https://dx.doi.org/10.29228/TurkishStudies.41667

Received/Geliş:07February/Şubat 2020

Accepted/Kabul:30April/Nisan 2020

Checkedbyplagiarism software

Copyright (C) INTAC LTD, Turkey

Published/Yayın: 30April/Nisan 2020

CC BY-NC 4.0 
areas which of one is educational management. Educational management is a separate department in education science and covers educational management, supervision, planning and economy. Educational management is the phase of performing aims on education and act together to reach expected goals (Sergiovanni, Burlingame, Coombs and Thurston, 1987). Educational supervision is to observe and evaluate teachers' planning, performing and practices. Education planning is evaluation of the possibilities arise during the process, determining aims of the education and the changes that will ocur with in this period, foresee the issues on education and offer solutions suitable to the issues (Harnquist, 1987). Education economy is the science connecting education and economy in terms of evaluation of human recourse development. Efficiency is improving the quality of good and products, presenting better life conditions to human recourse and the effort of having better quantity of product.

\section{Method}

This study aims to evaluate the efficiency of educational management master programs. This is a quantitative study designed as survey model. Survey models aim to describe a situation in its current structure. Besides survey models aim to explain the subject of the research in its own conditions (Karasar, 1984). In this context, this study aims to explain the efficiency level of educational management master programs in its own conditions and the ideas of the students on programs were examined. This study has been applied with 334 participants studying at department of educational management master degree programs. 'Efficiency scale' developed by Özcan (2014) was used for data collection. In total 334 scale form was carefully filled and used for analyse. In 'Efficiency scale there are 25 items and 3 sub-dimensions. Subdimensions of the scale are 'Master courses and evaluation', 'Beneficiary level of the participants from the program', 'physical conditions and lecturing'. Cronbach Alpha value of the scale is .91, Kaiser-Meyer-Olkin (KMO) value of the scale is .935, and Bartlett's test of sphericity value of the scale is 4813,985 . SpearmanBrown coefficient is 89 and Guttman coefficient is .88. Research data was analysed by SPSS 18 packet program and t test and one way ANOVA and Tukey test were used for data anayse. Signicinant level of the analyse was determined as .05.

\section{Results, Discussion and Conclusion}

According to the research findings, efficiency of the program is significantly differ according to the age variable $(p<.05)$ and the items with the highest difference are 'Classroom materials are met with the needs', 'Classroom environment is designed suitable for lecture', 'The program is designed to meet the expectation of the students', 'Advised materials are scientifically met with the needs of the students', 'Suitable method and techniques were used at lectures', 'Lecturers are in positive attitudes and behaviours to students', 'Objective criteria are used for evaluation at the end of the term'. Efficiency of the program is significantly differ according to the professional experience $(p<.05)$ and the items with the highest difference are 'Content of the program is suitable for the purpose', 'Program is enough to gain theoretical knowledge', 'Subject becomes more understandable by using educational visual technologies', 'Suitable method and techniques were used at lectures', 'Assessment and evaluation system has positive effects on the student'. Efficiency of the program does not significantly differ according to school type variable ( $p>.05)$. Efficiency of the program is significantly differ according to administrative position variable $(p<.05)$. The items with the highest difference are 'Physical conditions (heat, light, ventilation) is sufficient', 'Financial recourses provide equipments related to lecture', 'Classroom materials are met with the needs', 'Subject becomes more understandable by using educational visual technologies' and 'Lecturers are in positive attitutes and behaviours to students' Efficiency of the program does not significantly differ according to master program type variable $(\mathrm{p}<.05)$. Human resource has become one of the most important factors on the world. States mostly use their human resources for their development. For this reason sectors that human resource take place and contributions of these human resource to states change. States mostly tend to educational systems for development and aims to become competitive with world. At this point education, educational management, efficiency of the educational system become an important issue. Accordingly states design their educational systems to improve the efficiency of the education by management, supervision, planning and economic dimensions. With graduation programs, higher education system aims to improve the human resource and scientific research quality. To reach this aim, one of the main expectation is to risen the efficiency of the master programs. To risen the efficiency of the master programs it is necessary to determine the factors negative effect.

Keywords: Education, Management, Educational Management, Master, Efficiency 
Öz: $\mathrm{Bu}$ araştırmanın amacı eğitim yönetimi alanında yürütülen yüksek lisans programlarının verimlilik düzeyi çeşitli değiş̧kenler açısından incelenmesidir. Araştırmada nicel veri toplama ve analiz yöntemleri kullanılmıştır. Araştırmabetimsel nitelikte olup, tarama modelinde desenlenmiştir. Bu çalışma ile eğitim yönetimi alanında yüksek lisans yapan öğrencilerin programa yönelik görüşleri Özcan (2014) tarafindan geliştirilen verimlilik Ölçeği kullanılarak belirlenmeye çalışılmıştır. Çalışmada kullanılan ölçek 25 madde ve 3 alt boyuttan oluşmaktadır. Bu alt boyutlar "Yüksek lisans dersleri ve değerlendirilmesi", "Programdan katılımcıların yararlanma düzeyi" ve " Fiziki şartlar ve derslerin işlenişi " olarak adlandırılmıştır. Ölçeğin faktör analizi sonucunda Kaiser-Meyer-Olkin (KMO) değeri .935, Bartlett's test of sphericity değeri ise 4813,985 olarak bulunmuştur. Ölçeğin Cronbach Alpha değeri .91, Spearman-Brown katsayısı 89 ve Guttmankatsayısı $.88^{\prime}$ 'dir. Araştırmanın örneklemi farklı üniversitelerin eğitim yönetimi alanında yüksek lisans programında eğitim alan 334 katılımcı oluşturmaktadır. Çalışmanın örneklemi amaçlı örnekleme yöntemi ile belirlenmiştir. Yaş, mesleki kıdem, okul türü, idari görev ve yüksek lisans türü araştırmada yer alan bağımsız değişkenlerdir. Araştırma sonuçlarına göre yaş değişkeniyükssek lisansın verimliliğini anlamlı düzeyde etkilemektedir. Mesleki kıdem açısından yükseklisans programının verimliliği anlamlı düzeyde farklılaşmaktadır. Okul türü yükseklisans programlarının verimliliğinde anlamlı bir farklılık oluşturmamaktadır. İdari görev değişkenine göre okul müdürü ile müdür yardımcısı arasında anlamlı bir farklılık görülmektedir. Son olarak program türlerinin verimlilikte anlamlı bir farklılık oluşturmadığı görülmüştür.

Anahtar Kelimeler: Eğitim, Yönetim, Eğitim Yönetimi, Yüksek Lisans, Verimlilik

\section{Giriş}

Eğitimin sürekli bir değişim ve gelişim göstermesi nedeni ile günümüze kadar birçok tanımlama yapılmıştır. Bununla birlikte genel bir tanımlama ile eğitim fiziki, fikri ve ahlaki becerilerin geliştirilmesi olarak tanımlanabilir (Lederman, 1992). Eğitime yönelik bir diğer tanıma göre eğitimin bireyin doğuştan getirdiği fiziksel ve fikri becerilerinin ve sonrasında edindiği ahlaki anlayışa yönelik amaçlı yapılan etkinliklerdir (Crowe, 1991). Tanımlar incelendiğinde eğitimin bireyde fikri, ahlaki değerler kazandırmasının yanında beceri de kazandırdığı ve bunun belirli bir amaçla ve programlı olarak yapıldığı anlaşılmaktadır. Eğitim süreç içinde alt alanlara ayrılarak mikro düzeyde odaklanılmıştır. Bu alt alanlar eğitimde program ve öğretim, program geliştirme, eğitimde yönetim, psikoloji, tarihi ve felsefesi, ölçme ve değerlendirme olarak ifade edilebilir. Bu araştırmada ise eğitimin bir alt alanı olan eğitim yönetimi, denetimi, planlaması ve ekonomisi anabilim dalında yapılan yükselisans programlarının verimliliği bu programda eğitim alan öğrenci görüşleri ile araştırılmıştır. $\mathrm{Bu}$ amaçla eğitim yönetimi, denetimi, planlaması ve ekonomisi kavramları, tarihsel gelişim süreci içinde ve bu çalışmanın kapsamına uygun olarak açıklanmıştır.

\section{Eğitim yönetimi denetimi planlaması ve ekonomisi alanlarının tarihçesi ve gelişimi}

Türkiye'de ve dünyada eğitim yönetimi son dönemlerde önem kazanmış ve araştırmaya değer görülmüştür. İlk kez Amerika'da eğitim yönetimi alanında araştırmalara başlanmış ve bu dönemden sonra tüm dünyada araştırmalar yapılarak kuram ve uygulama açısından eğitim yönetimi alanı uzmanlaşmıştır (Papa, 2009). Eğitim yönetimi eğitime yönelik amaçların gerçekleştirilmesinde ve beklenen sonuca ulaşılmasında birlikte çalışma aşamasıdır (Sergiovanni, Burlingame, Coombs ve Thurston, 1987). Bu tanımlar ile eğitim yönetiminin sistemin ve okullaşmanın önemli bir paydaşı olduğu ortaya çıkmaktadır. Dolayısıyla eğitim yönetimi alanının geçmişten günümüze hangi aşamalardan geçerek bugünkü durumuna geldiğinin ortaya çıkarılması alanın geleceği açısından önemlidir (Papa, 2009). Öncelikle bir bilim alanı olan eğitim yönetiminin okullar için uygulama açısından büyük önem taşımasının yanında üniversiteler içinde bir disiplin alanı olduğu ve konunun bu açıdan da incelenmesi beklenmektedir.

Türkiye'de eğitim yönetiminin gelişimi incelendiğinde geçmişten günümüze alanın gelişim sağladığı ve öneminin vurgulandığı görülmektedir. Bu dönemlerde ise eğitim yönetimi alanı eğitim 
sistemi içinde yer edinmiştir. Cumhuriyet tarihi ile gelişimi incelenecek olursa 1924 yılında eğitim sisteminin tek bir çatı altında toplanması, Dewey'in Türkiye'deki eğitim sistemine yönelik yazdığ rapor, Öğretmen yetiştirmek amacı ile kurulan Orta Muallim Okulu (Gazi Eğitim Fakültesi), 1964 yılında Ankara Üniversitesi'ne bağlı eğitim fakültesinin kurulması ve diğer üniversitelere bağl1 olarak eğitim fakültelerinin kurulması ve öğretmen yetiştirmesi, yüksek öğretim kurulu, milli eğitim şuraları, uluslararası belgelerin eğitim sistemine katkıları, eğitime yönelik yasa ve yönetmelikler alana katkılar sağlamıştır (Bursalığlu, 2000; Sakaoğlu, 2003; Turan, 2000).

1953 yılında TODAİE (Türkiye Ortadoğu Amme İdaresi Enstitüsü) ve 1963 yılında MEHTAP (Merkezî Hükümet Teşkilâtı Araştırma Projesi) ile eğitim yönetimi alanı ayrı bir disiplin olarak kabul edilmiştir (Şişman ve Turan, 2004). Bu öneri ile birlikte eğitim yönetimi üniversitelerde ayrı bir disiplin alanı olma yoluna gitmiştir (Örücü ve Şimşek 2011). Son yıllarda ise bilimsel çalışmaların yanında eğitim yönetimi dernek, kongre ve diğer faaliyetlerle kurumsallaştırılmıştır. EYEDDER (Eğitim Yöneticileri ve Eğitim Deneticileri Derneği), Eğitim yönetimi kongreleri, Eğitim yönetimi alanında uzman bilim insanlarının toplantı ve raporları eğitim yönetimi alanında akademik bir örgütlenmenin olduğunu ortaya çıkarmaktadır.

Yönetim alanına yönelik yapılan çalışmalar incelendiğinde, araştırmaların çok yönlü olarak değiştiği görülmektedir. Araştırmacılar eğitim yönetimi teorilerini (Bush, 2006), okul yöneticilerinin liderlik özelliklerini (Amanchukwu ve Stanley ve Ololube, 2015), cinsiyete göre okul yöneticilerinin farklılıklarını (Pounder ve Coleman, 2002), okula dayalı yönetim modelllerini çalışmaktadır (Abu-Duhuo, 1999).

Denetim en genel ifadeyle yapılan işin amacına yönelik olup olmadığı, hangi düzeyde amacına yönelik yapıldığının araştırılması olarak tanımlanabilir. Eğitim isteminde de denetim faaliyetleri yürütülmektedir. Bu faaliyetler okul yöneticilerine, harcamalara, düzenlemelere uyum ve ögretmenlerin derslerine yönelik yapılmaktadır. Eğitim sistemi içinde yapılan denetim teknik olmasının yanında öğretmene güven vermesi de beklenmelidir. Başka bir ifade ile denetim aynı zamanda öğretmeni geliştirici rehberlik niteliği de taşıması beklenir. Öğretmenlerin ders içi uygulamaları öğretmene olumsuz güven verecek nitelikte kullanılmaması da beklenir (Acheson ve Gall, 1997). Bu doğrultuda yapılan denetim sistemi öğretmene güven verecek ve kendini geliştireceği inancını ortaya çıkaracaktır.

Eğitimde denetim sistemini temellendirmek amacıyla çerçeve planı hazırlanabilir (Bittel, 2005). Böylece öğretmen dersinin amaç ve içeriğini gözden geçirerek anlatacaklarını, planlarını, kullanacağı teknik ve yöntemleri denetim sistemi ile paylaşabilir. Bunun karşılığında denetmen ise öğretmenin planlarını, anlatacağı konu için kullanacağ 1 yöntem ve teknikleri ve bunların konuya uygunluğunu gözden geçirir (Pajak, 2003). Ayrıca öğretmenlere denetimin ne zaman ve hangi amaçla yapılacağı, denetim sonrası nelerin yapılacağının açıklanması öğretmenin daha bilinçli ve güvenli bir denetim geçirmesini sağlayabilir.

Eğitim yönetiminin denetimine yönelik olarak yapılan çalışmalar genel olarak okul ve okul yöneticilerine ve öğretmenlere odaklanılmaktadır. Bu bağlamda öğretmenlerin denetimlerinin eğitime yansımaları (Ebmeier, 2003), öğretim denetim modelleri (Gebhard, 1984), denetim ile motivasyon arasındaki ilişki düzeyi (Sianturi, Napitupulu ve Purba, 2020), klinik denetim modeli (Jibson, Casher ve Figueroa, 2020) çalışma alanları kapsamına girmektedir.

Planlama yapılacak bir işin eldeki materyal ve malzemenin en doğru şekilde kullanılarak amacına uygun olarak yapılabilmesi için sürecin aşamalandırılması olarak tanımlanabilir. Eğitim ise bir süreç olduğu düşünülürse var olan insan kaynağının ve diğer kaynakların amacına uygun olarakkullanılması sürecinin aşamalandırılması olarak ifade edilebilir. Eğitim planlaması süreç içinde ortaya çıkabilecek olasılıkları değerlendirmek, eğitim sisteminin amaçlarını ve süreç içinde meydana gelecek değişimi belirlemek, ortaya çıkacak sorunları öngörmek ve bu sorunlara yönelik çözüm önerileri getirebilmek olarak tanımlanabilir (Harnquist, 1987). 
Gibbon'a(2000) göre eğitim planlaması kaynakların doğru kullanılması açısından mevcut sorunların çözüme kavuşturulması, amaçlara en kısa ve en iyi şekilde ulaşılması için girdilerin sisteme dâhil edilmesi ve bu girdilerin kullanılmasına yönelik sürecin kararlaştırılmasıdır. Başka bir ifadeyle eğitim planlaması mevcut kaynaklar ile eğitim sisteminde ulaşılmak istenen amaçların gerçekleştirilmesi sürecidir. Eğitim planlaması ülkenin bütçesi içinden amaçlara uygun olarak alınan kaynağın eğitimin amaçlarına uygun olarak aktarılması sonrası, kaynakların eğitimin ihtiyaçlarına uygun olarak paylaşılması ve kullanılmasının şekillendirilmesi sürecidir (Hesapçığlu, 1984). Toplumda hızlı bir değişim ve gelişim yaşanmaktadır. Bu değişim ve gelişim tüm alanlarda olduğu gibi eğitim sisteminde de yaşanmaktadır. Her bir nesil bir önceki nesilden farklı beklenti ve ihtiyaçlarla eğitim sistemine girmektedir. Eğitim sisteminin geleceği çevresel değişimlere ve gelişimlere bağlıdır. Eğitimin planlaması bu açıdan bakıldığında eğitimin geleceğinin kurulması için gösterilen bir çabadır. Ancak eğitimde yaşanacak değişim ve gelişmeleri önceden kestirmek oldukça güçtür. Eğitimde yapılan planlama ise bu anlamda özel bir anlam taşımaktadır.

Eğitim sisteminde yaşanacak değişim ve gelişmeleri görebilmek için ise bilimsel araştırmaların yanında toplumsal araştırmalar, teknolojik araştırmalar ve uluslar arası düzeyde gelişmiş toplumlar gözlemlenebilir. Bunun sonucunda ise eğitim sisteminde yaşanacak gelişim ve değişimler daha somut verilere dayalı ve geçerli bir planlama ile kontrol altında tutulabilir.

Eğitimin planlamasına yönelik çalışmalar yönetimden bağımsız olarak görülmemiş ve eğitim kurumlarının kalitelerinin artırılmasına (Ghatole ve Dahikar, 2020), akademik takvim ve eğitim programlarının planlanmasına (Sugianto, 2020), eğitim sisteminde yer alacak çalışanların eğitiminin planlanmasına (Yulianti ve Munir, 2020) yönelik çalışmalar yapılmıştır.

Ekonomi kavramı alanyazında birçok şekilde tanımlanmıştır. Bu tanımlara göre ekonomi kelimse eldeki kıt kaynakların özenli ve bir mantık çerçevesinde kullanılarak tasarruf edilmesi olarak tanımlanmaktadır (Hanson, 1985). Ekonomi kurum ve bireylerin, devletin ve özel işletmelerin kaynakların üretilmesine ve kullanılmasına yönelik olarak kararların alınmasını ve uygulanmasını ifade eder (Goldin, Katz ve Kuziemko, 2006).Uzmanlara göre ekonomigünümüzde ya da gelecekte tüketilmek üzere belirli bir zamanda bir malı üretmek, üretilen malı insanlar arasında paylaşmak ve kullanılmasına yönelik tercihleri inceleyen bir bilim dalıdır (Dynarski ve Scott-Clayton, 2006).

Tüm alanlarda olduğu gibi ekonomi kavramı eğitim sistemi içinde yer almaktadır ve eğitim sistemini ekonomik açıdan daha verimli hale getirebilmek için sisteme etki edebilmektedir. Eğitim ekonomisi, eğitim ile ekonomi arasında bağlantı kuran, insan kaynakları ile gelişmeler arasında yaşanan süreci doğru bir şekilde görebilen ve bunların nedenlerini açılayan bir bilim dalıdır. Carnoy'e (1982) göre eğitim ekonomisi bireylerin ve bu bireylerin içinde yaşadığı toplumların daha üretken bir planlama yapmalarına da destek olmaktadır. Eğitim ekonomisi eğitime yönelik ekonomik değerlerin hangi ölçütlere göre ölçülmesi gerektiğine, eğitimde kullanılan kaynakların daha verimli ve etkili şekilde nasıl kullanılacağına, eğitimde yer alan insan kaynağının, ücretlendirilmesinde hangi yöntem ve verilerin esas alınması gerektiğine, eğitimin planlanmasına ve sürecin ekonomik açıdan işletilmesine yönelik bilimsel araştırmalar yaparak eğitim ekonomisine katk1 sağlar (Psacharopoulos, 1995).

\section{Verimlilik}

Verimlilik kavramı en genel anlamıyla üretim sürecine dâhil edilen tüm faktörlerin, süreç sonunda elde edilen ürünler ile arasındaki ilişkiyi ifade etmektedir. Prokopenko'ya (2005) göre verimlilik kaynakların en iyi biçimde değerlendirilmesi sürecidir. Verimlilik kavramı ayrıca üretim sürecine dâhil edilen mal ve hizmetin kalitesinin artırılması, üretim sürecinde yer alan insan kaynağına en iyi yaşam koşullarını sunabilme ve girdilerden en fazla çıktıyı alabilme çabası olarak ifade edilebilir (Ramsay, 2008). Uzun dönemli ve yüksek maliyetli bir yatırım olan eğitimin verimli olması bu kapsamda yaratıcı ve üretken bireyleri topluma kazandırmak büyük önem 
taşımaktadır (Demirci, 2011). Eğitim sisteminin verimli olması ile bilgi seviyesi yüksek, bireysel ve evrensel kültüre sahip, değişimi ve gelişimi takip eden bireyler yetişitrilir. (Çakmak,2008).

$\mathrm{Bu}$ çalışma ile eğitim yönetimi yükseklisans programlarının verimlilik düzeyleri yaş, mesleki kıdem, okul türü, idari görev ve yüksek lisans türü değişkenleri açısındanincelenmiştir. Araştırmanın yöntemi, elde edilen bulgular ve önceki çalışmalar ile benzerlikleri aşağıda ele alınmıştır.

\section{Yöntem}

\section{Araştırma modeli}

$\mathrm{Bu}$ araştırma eğitim yönetimi alanında yapılmış yüksek lisans programlarının verimlilik düzeyini araştırmayı amaçlamaktadır. Çalışma Betimsel nitelikte olup, tarama modeline göre desenlenmiştir. Tarama modelleri var olan bir durumun mevcut haliyle ve kendi koşulları içinde betimlenmesini amaçlayan araştırma türüdür. (Karasar, 2009). Bu kapsamda mevcut araştırmada eğitim yönetimi yüksek lisans programlarının verimlilik düzeyleri var olan hali ile açıklanmaya çalış1lmış ve programda eğitim gören öğrencilerin programa yönelik görüşleri incelenmiştir.

\section{Çalışma evreni ve örneklem}

Araştırmanınevrenini Türkiye'nin devlet, vakıf ve özel üniversitelerinin eğitim yönetimi alanında yüksek lisans programında en az bir yarıyıl eğitim almış öğretmen ve okul yöneticileri olan ögrenciler oluşturmaktadır ve amaçlı örnekleme yöntemi ile belirlenmiştir. Araştırma toplam 334 katılımcı ile yapılmıştır.

Aşağıda Tablo 1'de eğitim yönetimi yüksek lisans programına katılan öğrencilerin cinsiyete göre betimsel istatistikleri verilmiştir.

Tablo 1:Calıșmada Yer Alan Katılımcıların Betimsel Analizi

\begin{tabular}{|c|c|c|c|}
\hline & & $\mathrm{f}$ & $\%$ \\
\hline \multirow{2}{*}{ Cinisyet } & Kadın & 125 & 37.4 \\
\hline & Erkek & 209 & 62.6 \\
\hline \multirow{7}{*}{ Yaş } & $22-25$ & 41 & 12.3 \\
\hline & $26-29$ & 77 & 23.0 \\
\hline & $30-33$ & 69 & 20.7 \\
\hline & $34-37$ & 58 & 17.4 \\
\hline & $38-41$ & 40 & 11.9 \\
\hline & $42-45$ & 21 & 6.3 \\
\hline & $46+$ & 28 & 8.4 \\
\hline \multirow{6}{*}{ Mesleki kıdem } & $1-3$ & 58 & 17.4 \\
\hline & $4-7$ & 79 & 23.7 \\
\hline & $8-11$ & 63 & 18.9 \\
\hline & $12-15$ & 60 & 18.0 \\
\hline & $16-20$ & 39 & 11.7 \\
\hline & $21+$ & 35 & 10.5 \\
\hline \multirow{8}{*}{ Okul türü } & Okul öncesi & 39 & 11.7 \\
\hline & İlkokul & 70 & 21.0 \\
\hline & Ortaokul & 72 & 21.6 \\
\hline & Genel lise & 27 & 8.1 \\
\hline & Anadolu lisesi & 55 & 16.5 \\
\hline & Meslek lisesi & 31 & 9.3 \\
\hline & Fen lisesi & 12 & 3.6 \\
\hline & Diğer & 28 & 8.4 \\
\hline \multirow{3}{*}{ İdari görev } & Okul müdürü & 32 & 31.4 \\
\hline & Müdür yardımcısı & 37 & 36.3 \\
\hline & Diğer & 33 & 32.3 \\
\hline \multirow{2}{*}{ Yükseklisans türü } & Tezli & 152 & 45.5 \\
\hline & Tezsiz & 182 & 54.5 \\
\hline
\end{tabular}


Tablo 1'de katılımcıların değişkenlere demografik bilgileri sunulmuştur. Buna göre ölçek 334 katılımcı tarafindan yanıtlanmıştır. Katılımcıların frekans ve yüzde bilgileri yukarıda Tablo 1 'de verilmiştir.

\section{Veri Toplama aracı}

Araştırmada Özcan (2014) tarafından geliștirilen verimlilik ölçeği kullanılmıștır. Ölçekte25 madde ve 3 alt boyut yer almaktadır. Bu alt boyutlar "Yüksek lisans dersleri ve değerlendirilmesi", "Programdan katılımcıların yararlanma düzeyi” ve " Fiziki şartlar ve derslerin işlenişi "dir. Ölçeğin Spearman-Brown katsayısı 89 ve Guttmankatsayısı .88'dir. Ölçeğin faktör analizine göreKaiserMeyer-Olkin (KMO) değeri .935, Bartlett's test of sphericity değeri ise 4813,985'dir. Cronbach Alpha değeri .91, yüksek lisans dersleri ve değerlendirilmesi alt boyutu Cronbach Alpha değeri .84, programdan katılımcıların yararlanma düzeyi alt boyutu Cronbach Alpha değeri .80 ve fiziki şartlar ve derslerin işlenişi alt boyutu Cronbach Alpha değeri .81 olarak bulunmuştur. Bu sonuçlar faktör analizi, varsayımlarının sağlandığı ve 3 faktörden oluşan ölçeğin toplam varyansın\% 56 'sını açıkladığı görülmektedir.

\section{Verilerin toplanması ve analizi}

Verilerin toplanılması sürecinde toplam 410 katılımcıya ölçek formu elden dağıtılması yolu ile ulaştırılmış ve 334 öğrenci formu analize katılacak düzeyde tamamlamıştır. Ölçeğin yanıtlama oranı ise \% 81.46'dır. Araştırmada kullanılan ölçeklerin doldurulması 30 günlük bir zaman diliminde tamamlanmış ve ölçekler analiz programı ile incelenmiştir. Analiz aşamasında veriler parametrik istatistik yöntemlerinin öncül kriteri olan normallik varsayımı Kolmogorov-Smirnov testi ile analiz edilmiş ve bağımsız örneklemler için t-Testi ve Tek Yönlü ANOVA ile Tukey çoklu karşılaştırma testleri uygulanmıştır. Araştırmanın anlamlılık düzeyi .05 olarak belirlenmiş ve betimsel istatistiklerden faydalanılmıştır.

\section{Bulgular}

$\mathrm{Bu}$ bölümde eğitim yönetimi yüksek lisans programlarının verimliliği yaş, mesleki kıdem, okul türü, idari görev ve yüksek lisans türü değişkenleri açısından incelenmiştir. Aşağıda Tablo 2'de ölçeğin ve alt boyutların betimsel analiz sonuçları verilmiştir.

Tablo 2: Ölçek ve Alt Boyutların Betimsel Analizi

\begin{tabular}{lccccc}
\hline Ölçek ve alt boyutlar & $\mathrm{N}$ & $\overline{\mathbf{x}}$ & $\mathrm{med}$ & $\mathrm{mod}$ & $\mathrm{ss}$ \\
\hline $\begin{array}{l}\text { Yükseklisans programlarının } \\
\text { verimliliği Ölçeği }\end{array}$ & & 2.43 & 2.60 & 2.92 & .49 \\
$\begin{array}{l}\text { 1. "Yükseklisans dersleri } \\
\text { ve değerlendirilmesi" }\end{array}$ & 334 & 2.50 & 2.70 & 3.00 & .52 \\
$\begin{array}{l}\text { 2. "Programdan } \\
\text { katılımcıların yararlanma düzeyi" }\end{array}$ & & 2.44 & 2.62 & 3.00 & .54 \\
\begin{tabular}{l} 
3. "Fiziki şartlar ve derslerin işlenişi" \\
\hline
\end{tabular} & 2.32 & 2.42 & 3.00 & .58 \\
\hline
\end{tabular}

Tablo 2 incelendiğinde katılımcıların yüksek lisanas programlarının verimliliğine ilişkin görüşlerinin olumlu düzeyde değerlendirdiği görülmektedir.

Aşağıda Tablo 3 de eğitim yönetimi yüksek lisans programının verimliliği yaş değişkenine göre incelenmiş ve anlamlı farklılığın yüksek çıktığı maddeler verilmiştir. 
Tablo 3:Yaş Değişkenine Göre Verimlilik Ölçeğine Yapılan Tek Yön ANOVA Testi Sonucunda Çıkan Bulgular

\begin{tabular}{lcccccc}
\hline Değişken & $\begin{array}{c}\text { Varyansın } \\
\text { Kaynağı }\end{array}$ & KT & Sd & KO & F & p \\
\hline \multirow{3}{*}{ Yaş } & Genel & 82.537 & 333 & & & \\
& Gruplar arası & 8.710 & 6 & 1.452 & 6.430 & .000 \\
& Gruplar içi & 73.826 & 327 & .226 & & \\
\hline
\end{tabular}

Tablo 3 incelendiğinde yaş değişkenine göre yükseklisans programlarının verimliliğinde anlamlı bir farklılık vardır. Buna göre anlamlı farklılığın en yüksek olduğu maddeler ve farklılık değerleri sırasıyla: Kullanılan araç gereçler derste ihtiyaçları karşılamaktadır $(p<.05)$. Derslerin yürütüldüğü sınıf ortamları öğretime uygun şekilde tasarlanmıştır $(\mathrm{p}<.000)$. Program öğrencilerin beklentilerine cevap verecek şekilde düzenlenmektedir $(\mathrm{p}<.05)$. Önerilen kaynaklar öğrencilerin bilimsel açıdan ihtiyaçlarını karşılayacak düzeydedir $(\mathrm{p}<.05)$. Derslerde konular uygun yöntem ve tekniklerle çalışılmaktadır $(\mathrm{p}<.05)$. Öğretim üyeleri öğrenciye karşı olan tutum ve davranışları olumludur $(\mathrm{p}<.05)$. Dönem sonunda objektif kriterlere göre değerlendirme yapılmaktadır $(\mathrm{p}<.05)$ maddeleridir.

Yapılan tukey testi sonuçlarına göre ise 26-29 ile 34-37; 30-33 ile 34-37; 34-37 ile 38-41; 34-37 ile 42-45 ve 34-37 ile 46 üstü yaş grupları arasında farklılık görülmüştür. Bu anlamlı farklılıkların sebepleri öğretmen kariyer evreleri ile açıklanabilir. Her kariyer evresindeki öğretmenin mesleki açıdan farklı beklentiler içindedir. Kariyer evresinin birinci basamağında olan öğretmenler beklentilerinin hemen karşılanması aksi durumda mesleğinden vazgeçme düşüncesi içindedir. İkinci basamakta olan öğretmenler mesleki açıdan araştırma düzeyindedir ve yüksek lisans beklentileri kendilerini tecrübelerinden de faydalanarak en üst düzeyde geliştirilmesi yönündedir. Üçüncü evrede olan öğretmenler ise yüksek lisans eğitiminin kendi tecrübelerine katkıda bulunacağ 1 ve doğrulayacağ 1 yönündedir.

Aşağıda Tablo 4'te eğitim yönetimi yüksek lisans programının verimliliği mesleki kıdem değişkenine göre incelenmiş ve anlamlı farklılığın yüksek çıktığı maddeler ve değerlendirmesi verilmiştir.

Tablo 4: Mesleki Kıdem Değişkenine Göre Verimlilik Ölçeğine Yapılan ANOVA Testi Sonucunda Çıkan Bulgular

\begin{tabular}{lcccccc}
\hline Değişken & $\begin{array}{l}\text { Varyansın } \\
\text { Kaynağı }\end{array}$ & KT & Sd & KO & F & p \\
\hline \multirow{3}{*}{ Mesleki Kıdem } & Genel & 82.537 & 333 & & & \\
& $\begin{array}{c}\text { Gruplar } \\
\text { arası }\end{array}$ & 3.483 & 5 & .697 & 2.890 & .014 \\
& Gruplar içi & 79.053 & 328 & .241 & & \\
\hline
\end{tabular}

Tablo 4 incelendiğinde mesleki kıdem değişkenine göre yükseklisans programlarınınverimliliğinde anlamlı bir farklılık vardır. Buna göre anlamlı farklılığın en yüksek olduğu maddeler sırasıyla: 'Programın içeriği amacına uygun.' $(\mathrm{p}<.05)$; 'Program teorik bilgilerin kazandırılması için yeterli.' ( $\mathrm{p}<.05)$; 'Programda eğitici görsel teknolojilerden yararlanılarak konu daha anlaşılır hale getirilmektedir.' $(\mathrm{p}<.05)$; 'Derslerde konular uygun yöntem ve tekniklerle çalışılmaktadır.' ( $p<.05)$ 'Ölçme değerlendirme sistemi öğrenci üzerinde olumlu etkilere sahiptir.' $(\mathrm{p}<.05)^{\prime}$ 'dir.

Ölçekte anlamlı farklılığın olduğu maddeler mesleki kıdem değişkenine göre incelendiğinde mesleki kıdemi çok olan öğrencilerin derste kullanılan araç gereçlerin ihtiyacı 
karşıladığını, sınıf ortamının eğitime uygun olduğunu, program içeriğinin amacına uygun ve yeterli olduğunu ifade ederken mesleki kıdemi az olan öğrenciler daha iyi olabileceğini belirtmişlerdir. Teknoloji açısından ise mesleki kıdemi yüksek olan öğrenciler ise teknolojiye ve bilimin teknoloji ile araştırılmasına derslerde teknolojinin kullanımına daha uzak dururken kıdemi az olan öğrencilerin teknolojiden daha çok yararlandıkları bu durumun ise verimliliği mesleki kıdem açısından etkilediği görülmektedir. Bu açıdan mesleki kıdemin yüksek lisans programının verimliliğini belirlemede önemli bir ölçüt olduğu söylenebilir. Yapılan tukey testi sonuçlarına göre ise 21 ve üzeri mesleki kıdeme sahip öğretmenler ile 8-11 ve 12-15 yıl mesleki kıdeme sahip olan öğretmenler arasında yükseklisans programının verimliliğine yönelik farklılıklar görülmektedir. $\mathrm{Bu}$ bulgular araştırmanın sonuçlarını destekler niteliktedir

Aşağıda Tablo 5'de eğitim yönetimi yüksek lisans programının verimliliği çalışılan okul türü değişkenine göre incelenmiş ve anlamlı farklılığın olduğu bir madde ve değerlendirmesi verilmiştir.

Tablo 5: Okul Türü Değişkenine Göre Verimlilik Ölçeğine Yapılan ANOVA Testi Sonucunda Çıkan Bulgular

\begin{tabular}{lcccccc}
\hline Değişken & $\begin{array}{l}\text { Varyansın } \\
\text { Kaynağ1 }\end{array}$ & KT & Sd & KO & F & p \\
\hline \multirow{3}{*}{ Okul Türü } & Genel & 82.537 & 333 & & & \\
& $\begin{array}{c}\text { Gruplar } \\
\text { arası }\end{array}$ & 1.570 & 7 & .224 & .903 & .504 \\
& Gruplar içi & 80.966 & 326 & .248 & & \\
\hline
\end{tabular}

Tablo 5 incelendiğinde okul türü değişkenine göre yükseklisans programlarının verimliliğinde anlamlı bir farklılık yoktur. Bu sonuç mesleki kıdem değişkeninin yükseklisans programlarının verimlilik düzeylerinde anlamlı düzeyde farklılık ortaya çıkarmadığını göstermektedir.

Aşağıda Tablo 6'da eğitim yönetimi yüksek lisans programının verimliliği idari görev değişkenine göre incelenmiş ve anlamlı farklılığın yüksek çıktığ 1 maddeler ve değerlendirmesi verilmişsir.

Tablo 6: İdari Görev Değişkenine Göre Verimlilik Ölçeğine Yapılan ANOVA Testi Sonucunda Çıkan Bulgular

\begin{tabular}{lllcccc}
\hline Değişken & $\begin{array}{l}\text { Varyansın } \\
\text { Kaynağ1 }\end{array}$ & KT & Sd & KO & F & $\mathrm{p}$ \\
\hline \multirow{4}{*}{ İdari Görev } & Genel & 26.245 & 101 & 1.58 & & \\
& $\begin{array}{l}\text { Gruplar } \\
\text { arası }\end{array}$ & 3.178 & 2 & 9 & 6.820 & .002 \\
& Gruplar içi & 23.067 & 99 & .233 & & \\
\hline
\end{tabular}

Tablo 6 incelendiğinde idari görev değişkenine göre yükseklisans programlarının verimliliği anlamlı düzeyde farklılık göstermektedir. Bu farklılık müdür ve müdür yardımcısı idari değişkenleri arasındadır. İdari görev değişkenine göre anlamlı farklılığın en yüksek olduğu maddeler ise sırasıyla Eğitim ortamının fiziki donanımı (Isı, 1ş1k, havalandırma vb.) yeterli $(\mathrm{p}<.007)$; Dersle ilgili araç gereç sağlamak için maddi kaynaklar yeterli $(\mathrm{p}<.000)$; Kullanılan araç gereçler derste ihtiyaçları karşılamaktadır $(\mathrm{p}<.000)$; Programda eğitici görsel teknolojilerden yararlanılarak konu daha anlaşılır hale getirilmektedir $(p<.001)$; Öğretim üyeleri öğrenciye karş1 olan tutum ve davranışları olumludur ( $\mathrm{p}<.005)$ 'dir. 
İdari görev değişkenine göre yapılan Tek yön Anova testinde anlamlı farklıllı̆ğı görüldüğü maddeler incelendiğinde idari görev değişkeninin yüksek lisans programının verimliliğini etkilediği görülmektedir. Bu durumun nedeni ise idari görevi olan öğrencilerin arasında müdür düzeyinde idari göreve sahip olanların yükseklisans yapılan dersliğin fiziki şartlarından, teknik donanımından, programın uygunluğundan ve amaca yönelik olduğundan memnun olduğu görülürken, müdür yardımcısı idari göreve sahip idarecilerin şartların kısmen yetersizliğinden, geliştirilmesinden yana olduğunu belirtmiş ve bu durumun yüksek lisansın yetersizliğine neden olduğunu ifade ettikleri görülmüştür. İdari görevi müdür olan katılımcıların mevcut şartlara kolay ulaşılmadığını bu yüzden yeterli olabileceğini ve yüksek lisans programının verimliliğinin bunlara bağlı olmayacağını belirttikleri, diğer idari göreve sahip olanların yüksek lisans programının tüm yönlerden gelişmesi gerektiğini ve bunların programın verimliliğini etkilediğini belirtmiştir. Yapılan tukey testi sonucunda ise müdür ve müdür yardımcısı idari görevi olan katılımcılar arasında yükseklisansın verimliliğine yönelik farklılık ortaya çıkmaktadır.

Aşağıda Tablo 7'de eğitim yönetimi yüksek lisans programının verimliliği yüksek lisans türü değişkenine göre incelenmiş ve anlamlı farkl1lığın olduğu maddeler ve değerlendirmesi verilmiştir.

Tablo 7: Yüksek Lisans Türü Değişkenine Göre Verimlilik Ölçeğine Yapılan t Testi Sonucunda Çıkan Bulgular

\begin{tabular}{lccccccc}
\hline Değişken & Kategori & $\mathrm{N}$ & $\overline{\mathrm{X}}$ & $\mathrm{ss}$ & $\mathrm{Sd}$ & $\mathrm{t}$ & $\mathrm{p}$ \\
\hline Yüksek Lisans & Tezli & 152 & 2.39 & .50 & \multirow{2}{*}{332} & -1.300 & .195 \\
Türü & Tezsiz & 182 & 2.46 & .49 & & \\
\hline
\end{tabular}

Tablo 7 incelendiğinde yükseklisans türü değişkenine göre yükseklisans programlarının verimliliği anlamlı düzeyde farklılık göstermemektedir. Bu sonuç yükseklisans programlarının verimliliğinin artırılmasında programın türününün önemli bir faktör olmadığ sonucunu ortaya çıkarmaktadır. Ayrıca bu sonuca göre yüksek lisans programlarında öğrenim gören öğrencilerin program türü fark etmeksizin eğitime gerekli özeni gösterdiği anlaşılmaktadır.

\section{Tartışma ve Sonuç}

İnsan kaynağı tüm dünyada önemli bir faktör haline gelmiştir. Ülkeler mevcut insan kaynaklarını ülkelerinin gelişimi açısından kullanmaktadır. Bu amaçla da insan kaynağının yer aldığı sektörler ve bu sektörlerin ülkeye katkıları nitelik olarak değişmektedir. Ülkeler bu aşamada öncelikle eğitime yönelmekte ve eğitimli bireyler ile gelişen dünya ile rekabet edecek düzeye gelmeyi amaçlamaktadır. Bu durumda ise eğitim sistemi, eğitim sisteminin yönetimi, sistemin çıktılarının verimliliği önem taşımaktadır. Dolayısıyla ülkeler eğitim sisteminin verimliliğini artırmaya yönelik eğitim sistemleri kurmakta, sistemi denetlemekte, planlamakta ve ekonomik açıdan değerlendirmektedir (Özdemir, 1995).

Yükseköğretim sisteminin bir eğitim kademesi olan yüksek lisans programları ile eğitimde başarının artırılması, bilimsel çalışmaların yapılması, projelerin geliştirilmesi, araştırmaların yapılması ve kalitenin artırılması hedeflenmektedir. Bu hedeflerin gerçekleştirilmesi için ise yüksek lisans programlarının verimli olması temel beklentilerdir. Ancak beklenen verimliliğin sağlanabilmesi için verimi düşüren etkenler tespit edilmeli ve ortadan kaldırılmalıdır (Pehlivan, 1992).

Bilişsel, duyuşsal ve psikomotor öğrenmeyi etkileyen temel faktörler 3 grupta toplanmaktadır. Bu faktörlerden öğrenci ilgileri kapsamında; başarıya odaklanmış yetenek testleri; büyüme oranları olgunlaşma ve kronolojik yaş; benlik kavramı ve motivasyon düzeyleri ile kişilik testleri ve çalışmaya istekli olma düzeyidir. Öğretim kapsamında öğrencinin öğrenmeye ayırdığı zaman ve programa göre öğretim yaşantılarının kalitesidir. Çevresel faktörler açısından ise aile yaşantısı, sınıf ortamı, akran grupları ve zaman kullanımıdır (Akkoyunlu ve Gücüm, 1988). 
$\mathrm{Bu}$ araştırma ile eğitim yönetimi alanında yüksek lisans yapan öğrencilerin yüksek lisansın verimliliği görüşleri araştırılmış ve bu kapsamda öğrencilerin yaş, mesleki kıdem, okul türü, idari görev ve yüksek lisans türü değişkenlerine bakılmıştır. Araştırma sonuçları incelendiğinde öğrencilerin yüksek lisansın verimliliği hakkındaki görüşlerinin çeşitli değişkenlere göre değiştiği görülmektedir. Genç öğretmenler teknolojiye daha yatkın ve teknolojiden yararlanmaya istekli oldukları görülmektedir Eğitimin verimliliğine yönelik yapılan çalışmalar incelendiğinde okul yöneticilerinin ve öğretmenlerin deneyimleri, becerileri, okulun fiziki şartları, laboratuar ve teknolojik altyapısı eğitimde verimliliği artıran niteliklerdir (Monk, 1990). Mesleki kıdem açısından bakıldığında mesleki kıdem ve deneyim arttıkça tecrübenin beklentiyi etkilediği ve öğretmenlerin mesleki tecrübelerini de yüksek lisansta kullanarak verimliliği artırdığı görülmektedir. Yaş ve mesleki kıdem kurumlarda verimlilik açısından anlamlı farklılık oluşturmaktadır (Tor ve Esengün, 2011). Okul türü değişkenine göre ise öğrencilerin görev yaptığ1 okulların verimlilikte önemli etkisinin olduğu görülmektedir. Akademik başarısı yüksek okullarda çalışan öğrenciler okulun fiziki ve teknolojik şartlarının iyi olmasından dolayı yüksek lisansın verimliliğinde olumlu etkiye sahip olduğunu belirtmektedirler. Yükseklisans türü değişkenine göre programın verimliliğinde anlamlı bir farkın olmadığı görülmektedir. Tezsiz yükseklisans programlarından genel olarak nitelikli öğretmen yetiştirme ve eğitimde kalitenin artırılmasına yönelik beklentilerin olduğu sonucu ortaya çıkmaktadır (Semerci ve Çerçi, 2005). Eğitim yönetimi yükseklisans programlarının niteliği okul yöneticilerinin verimliliğine önemli düzeyde etki etmektedir (Üstüner ve Cömert, 2007).

Genel olarak bakıldığında ise eğitim yönetimi alanında yapılan yüksek lisans eğitiminde ders içeriği, akademik çalışma, fiziki şartlar, kütüphane hizmetleri, araştırma olanakları, danışmanlık imkânlarının yeterli olduğu ve bu durumun verimlilikte artış sağladığı söylenebilir. Dersliklerin görsel ve işitsel açıdan fiziki şartları verimliliği önemli düzeyde etkilemektedir (Ekinci ve Bal, 2012). Okulun fiziki yapısı öğrencinin akademik başarısında önemli bir etkendir (Akbaşl, Kösece ve Uçan, 2018). Sınıfın fiziki özellikleri ile öğrenci başarısı arasında anlamlı bir ilişki vardır (Al Şensoy ve Sağsöz, 2015). Derslerin müfrdata uygun olması, planlı bir ders yapılması, iletişim kanallarının açık olması, öğrencilerin derse katılması sınıfta verimliliği etkileyen önemli kavramlardır (Gökçe, 2002). Yükseklisans eğitiminde alınan dersler öğretmen ve yöneticilerin mesleki gelişimine katkı sağlamaktadır (Turhan ve yaraş, 2013).

\section{Öneriler}

Eğitim yönetimi, denetimi, planlaması ve ekonomisi üzerinde sıç̧a çalışılan güncel konular arasındadır. $\mathrm{Bu}$ nedenle verilen eğitimlerde sıkça değişim gösterebilir. Araştırma sonuçlarına göre yükseklisans programları "Yüksek lisans dersleri ve değerlendirilmesi", "Programdan katılımcıların yararlanma düzeyi” ve " Fiziki şartlar ve derslerin işlenişi " olmak üzere 3 alt boyutta yeniden gözden geçirilerek güncellenebilir. Buna göre yükseklisans programında yer alan dersler ve içerikleri eğitimin yönelimleri dikkate alınarak belirlenebilir. Bu amaçla diğer üniversitelerle ortak çalışmalar gerçekleştirilerek içerik ve kapsam düzenli olarak çağın eğitim gereksinimlerine uyarlanabilir. Bunun sonucunda yükseklisans eğitimi alan katılımcılar güncel eğitim yönetimi konularına hâkim olur ve programdan en iyi düzeyde yararlanır. Ayrıca programın verimliliğinin artırılmasında bir diğer önemli konu ise fiziki şartlar ve eğitim sürecidir. Programın müfredatına teorik derslerin yanında uygulamalı dersler de eklenerek katılımcılara sahayı inceleme firsatı da verilebilir. Bu durumda katılımcı bir eğitim sisteminin yönetimine, denetimine, planlamasına ve ekonomisini yerinde öğrenmiş olur. 


\section{Kaynakça}

Abu-Duhuo, I. (1999). School-Based Management. Fundamentals of Educational Planning Series. Paris: UNESCO/International InstituteforEducational Planning.

Acheson, K. A. ve Gall, M. D. (1980). Techniques in theclinicalsupervision of teaches' preserviceandinserviceapplications. New York: Longman, Inc.

Akbaşl1, S., Kösece, P. ve Uçan, M. B. (2018). Okul değişkenlerinin akademik başarıya olan etkisine yönelik öğrenci görüşlerinin çeşitli değişkenler açısından incelenmesi. ScientificEducationalStudies, 2(2), 93-110.

Akkoyunlu, B. ve Gücüm, B. (1988). Eğitimde verimlilik kuramı üzerine. Hacettepe Üniversitesi Eğitim Fakültesi Dergisi, 3(3), 125-128.

Al Şensoy, S. ve Sağgöz, A. (2015). Öğrenci başarısının sınıfların fiziksel koşulları ile ilişkisi. Journal of KirsehirEducationFaculty, 16(3), 87-104.

Amanchukwu, R. N., Stanley, G. J. ve Ololube, N. P. (2015). A review of leadershiptheories, principlesandstylesandtheirrelevancetoeducationalmanagement. Management, 5(1), 6-14.

Balc1, A. (1988). Etkili okul. Eğitim ve Bilim, 12(70), 21-30

Bittel, L. R. (2005). Improvingsupevisorytasks. Aucklard: McGrawHill.

Bursalıoğlu, Z. (2002). Okul yönetiminde yeni yapı ve davranış. Ankara: Pegem A Yayıncılık.

Bush, T. (2006). Theories of Educational Management. International Journal of EducationalLeadershipPreparation, 1(2), 1-25

Carnoy, M.(1989). Eğitim ve ekonomi ilişkisi (Çev.Nejla T.). Ankara Üniversitesi Eğitim Bilimleri Fakültesi Dergisi, 22(1) 485-504.

Crowe, M. J. (1991). History of science: A guideforundermasters. Gainesville, FL: History of ScienceSociety.

Çakmak, Ö. (2008). Eğitimin Ekonomiye ve Kalkinmaya Etkisi. Dicle Üniversitesi Ziya Gökalp Eğitim Fakültesi Dergisi, 11, 33-41.

Demirci, S. F. (2011). Eğitim ve verimlilik. Bilim ve Aklın Aydınlığında Eğitim, 141, 14-21.

Dynarski, S. ve Scott-Clayton, J. (2006). Thecost of complexity in federal studentaid. NationalTaxJournal, 59, 319-56.

Ebmeier, H. (2003). How supervisioninfluencesteacherefficacyandcommitment: An investigation of a path model. Journal of Curriculumandsupervision, 18(2), 110-141.

Ekinci, C. E. ve Bal, S. (2012). Etkili Ve Verimli Eğitim İçin Dersliklerin Fiziki Ortam Özelliklerinin İncelenmesi. EngineeringSciences, 7(1), 96-105.

Gebhard, J. G. (1984). Models of supervision: Choices. TESOL Quarterly, 18(3), 501-514.

Ghatole, S. M. veDahikar, P. B. (2020). QualityPolicy Design forProblems in EducationalInstitutions. OurHeritage, 68(9), 47-51.

Gibbon, F. T. (2000). Monitoringeducation. London: Continuum.

Goldin, C., Katz, L. F. ve Kuziemko, I. (2006). Thehomecoming of Americancollegewomen: Thereversal of thecollegegendergap. Journal of Economicperspectives, 20(4), 133-156.

Gökçe, E. (2002). İlköğretim öğrencilerinin görüşlerine göre öğretmenlerin etkililiği. Ankara Üniversitesi Eğitim Bilimleri Fakültesi Dergisi, 35(1), 111-119. 
Hanson, E. M. (1985). Educationaladministrationandorganizationalbehaviour. California: Allynand Bacon.

Harnquvist, K. (1987). Socialdemandmodels, economics of educationresearchandstudies. PergamonPress.

Hesapçığlu, M.(1984) Eğitim planlaması ve yönetim. İstanbul: Marmara Üniversitesi yayınları.

Jibson, M. D., Casher, M. I. ve Figueroa, S. R. (2020). How toapproachclinicalsupervision. In Roberts AcademicMedicineHandbook (pp. 91-103). Springer, Cham.

Karasar, N. (2009). Bilimsel araştırma yöntemi: kavramlar-ilkeler-teknikler. Nobel Yayın Dağıtım.

Lederman, N.G. (1992). Students' andteachers' conceptions of thenature of science: A review of theresearch. Journal of Research in ScienceTeaching, 26(9), 771-783.

Monk, D. H. (1990). Educational Finance. An EconomicApproach. New York: McGrawHill Publishing Company.

Örücü, D. ve Şimşek, H. (2011). Akademisyenlerin gözünden Türkiye'de eğitim yönetiminin akademik durumu: Nitel bir analiz. Kuram ve Uygulamada Ĕ̈itim Yönetimi, 17(2), 167197.

Özcan, M. (2014). Eğitim yönetimi denetimi planlaması ve ekonomisi yüksek lisans programının verimliliğinin ve etkililiğinin değerlendirilmesi. Yayımlanmamış Yüksek Lisans Tezi. İstanbul: Marmara Üniversitesi Eğitim Bilimleri Enstitüsü.

Özdemir, S. (1995). Eğitimde verimlilik ve toplam kalite yönetimi. Kuram ve Uygulamada Eğitim Yönetimi, 3(3), 377-388.

Pajak, E. (1993). Thecentralofficesupervisor of curriculumandinstructionsettingthestageforsuccess. Boston: Allynand Bacon.

Papa, R. (2005). Thediscipline of educationadministration: Creditingthepast. InCreighton, T, Harris, S. andColeman, J. (Eds.). Creditingthepast, challengingthepresent, creatingthefuture, nationalcouncil of professors of educationaladministration, Texas.

Pehlivan, İ. (1992). Hizmet içi eğitim-verimlilik ilişkisi. Ankara Üniversitesi Eğitim Fakültesi Dergisi, 27(1), 151-162.

Pounder, J. S. ve Coleman, M. (2002). Women-betterleadersthan men? In general andeducationalmanagement it still "alldepends". Leadership\&Organization Development Journal23(3), 122-133

Prokopenko, J. (2005). Verimlilik yönetimi uygulamalı el kitabı (Çev: Olcay Baykal). Ankara: Milli Prodüktivite Merkezi Yayınları.

Psacharopoulos, G. (1995). Eğitim plânlaması: şu anda neredeyiz? (Çev. Parvin Nadim). Marmara Üniversitesi Eğitim Bilimleri Dergisi, 7, 221-231.

Ramsay, M.R. (2008) İşletme verimliliği ölçümü ve uluslararası işgücü verimliliği elkitabı. Ankara: Mpm Yayınları.

Sakaoğlu, N. (2003). Osmanlı'dan günümüze eğitim tarihi. İstanbul: Bilgi Üniversitesi Yayınları.

Semerci, N. ve Çerçi, A. (2005). Öğretmen yetiştirmede tezsiz yüksek lisans programı ve gelecekten beklentiler. Eğitim ve Bilim, 30,136), 52-60

Sergiovanni T. J., Burlingame, N., Coombs, F. S., ve Thurston, P. W. (1987). Educationalgovernanceandadministration. New Jersey: Prentice- HallInc. 
Sianturi, R. B., Napitupulu, E. ve Purba, S. (2020). Therelationshipbetweenworkmotivationandacademicsupervisionwiththeteachers'performan ce at pangkatanvocationalschool. Jurnal Prointegrita, 3(3), 432-439.

Sugianto, A. (2020). Individual Learning Plans Program Evaluation of Planning Education in Junior High School: Discrepancy Model. In Journal of Physics: Conference Series (Vol. 1422, No. 1, p. 012035). IOP Publishing.

Şişman, M. ve Turan, S. (2004). Eğitim yönetiminin gelişimi, Y. Özden (Ed), Eğitim ve okul yöneticiliği el kitabı. Ankara: Pegem Yayınları.

Tor, S. S. veEsengün, K. (2011). Örgütlerde iş tatminini etkileyen demografik faktörler ve verimlilik: Karaman gıda sektöründe bir uygulama. KaramanoğluMehmetbey Üniversitesi Sosyal ve Ekonomik Araştırmalar Dergisi, 13 (20), 53-63

Turan, S. (2000). John Dewey'sreport of 1924 and his recommendations on theTurkisheducationalsystemrevisited. History of Education, 29(6), 543-55

Turhan, M. ve Yaraş, Z. (2013). Lisansüstü programların öğretmen, yönetici ve denetmenlerin mesleki gelişimine katkısı. Elektronik Sosyal Bilimler Dergisi, 12(43), 200-218

Üstüner, M. ve Cömert, M. (2007). Eğitim yönetimi teftişi planlaması ve ekonomisi anabilim dalı lisansüstü dersleri ve tezlerine ilișkin bir inceleme. Kuram ve Uygulamada Eğitim Yönetimi, 55, 497-515

Yulianti, R. veMunir, M. (2020, February). Recruitment Planning of TeachersandEducationStaff at MTsYaspinaCianjur. In 3rd International Conference on Research of Educational Administration and Management (ICREAM 2019) (pp. 130-133). Atlantis Press. 